\title{
Morphological analysis of the sheathed flagellum of Brucella melitensis
}

Jonathan Ferooz ${ }^{1,2}$, Jean-Jacques Letesson ${ }^{1 *}$

\begin{abstract}
Background: It was recently shown that B. melitensis is flagellated. However, the flagellar structure remains poorly described.

Findings: We analyzed the structure of the polar sheathed flagellum of B. melitensis by TEM analysis and demonstrated that the Ryu staining is a good method to quickly visualize the flagellum by optical microscopy. The TEM analysis demonstrated that an extension of the outer membrane surrounds a filament ending by a club-like structure. The $\triangle f t c R, \triangle f l i f, \triangle f l g E$ and $\triangle$ fliC flagellar mutants still produce an empty sheath.

Conclusions: Our results demonstrate that the flagellum of $B$. melitensis has the characteristics of the sheathed flagella. Our results also suggest that the flagellar sheath production is not directly linked to the flagellar structure assembly and is not regulated by the FtcR master regulator.
\end{abstract}

\section{Background}

Brucellae are gram-negative, intracellular pathogenic bacteria that cause brucellosis in a variety of mammals, including humans. During a long time, they were considered as unflagellated. However, the presence of a sheathed flagellum has recently been discovered in Brucella melitensis $[1,2]$.

The fact that the flagellum was never previously observed in Brucella is probably due to the very short period (the early exponential growth phase in rich liquid medium) during which the flagellum is produced. The availability of the genome sequences of Brucella melitensis and Brucella suis revealed the presence of all the flagellar genes needed for the construction of a functional flagellum, except the genes encoding the chemotactic system $[3,4]$. Today, the sequence of the genome of $B$. abortus, B. ovis, B. canis and B. microti are available, showing that flagellar genes are also present in these species [5-7]. Interestingly, the presence of mutations in several flagellar genes in the different Brucella species suggest that the flagellar regulon contains pseudogenes and that the filamentous appendage observed is a flagellum-derived structure [5].

\footnotetext{
* Correspondence: jean-jacques.letesson@fundp.ac.be

${ }^{1}$ Unité de Recherche en Biologie Moléculaire (URBM), Facultés Universitaires Notre-Dame de la Paix (FUNDP), 61 rue de Bruxelles, B-5000 Namur, Belgium Full list of author information is available at the end of the article
}

The flagellum is a complex machine divided in three main structures [8]. The basal body structure is embedded in the membranes and functions like a tiny engine containing a motor, a stator and a secretion system. The hook structure is a universal joint transmitting the energy generated by the basal body to the filament. Finally, the filament is the most visible part of the flagellum and is made of about 20,000 monomers of flagellin with a length of several $\mu \mathrm{m}$. The control of the flagellar assembly is a fine-tuned mechanism well described in Salmonella enterica serovar Typhimurium, Escherichia coli and Caulobacter crescentus (for reviews, see the references [9-12]).

It was recently described that flagellar regulation of B. melitensis was controlled by the FtcR flagellar master regulator which activates flagellar expression by binding directly on fliF promoter [13]. The mutation of $f t c R$ decreases fliF expression and induces the extinction of the flagellin and hook proteins. The two LuxR-type regulators $\mathrm{VjbR}$ and $\mathrm{BlxR}$ are also required for flagellar activation $[14,15]$. VjbR is involved in the quorum sensing of $B$. melitensis and mediates the inhibitory effect of the $N$-dodecanoyl-DL-homoserine lactone (C12-HSL) [16]. In the early steps of the hierarchical flagellar regulation of $B$. melitensis, it was proposed that VjbR controls the expression of $f t c R$ [13]. More recently, it was proposed that flagellar hierarchy is divided in three 
classes in B. melitensis (J. Ferooz et al., unpublished). In this later work, FlbT was described as the checkpoint regulator between the class II and III genes, and activates the flagellin production.

Here, we demonstrate that the extracellular appendage produced by $B$. melitensis is a flagellum with all characteristics of the sheathed flagella. Moreover, $\Delta f t c R, \Delta f l i F$, $\triangle f l g E$, and $\triangle f l i C$ mutants still produce a filament, probably an empty sheath regulated independently of the $f t c R$ and $v j b R$ flagellar pathway.

\section{Materials and methods}

\section{Bacterial strains and culture conditions}

All strains used in this study are listed in Table 1. All Brucella strains used in this study derive from B. melitensis 16 $\mathrm{M} \mathrm{Nal}^{\mathrm{r}}$ (spontaneous nalidixic acid resistant mutant selected from B. melitensis $16 \mathrm{M}$, received from A. Macmillan, Central Veterinary Laboratory, Weybridge, UK). The growth was measured by reading the optical density of the cultures at $600 \mathrm{~nm}$. B. melitensis $16 \mathrm{M}$ growth curves in rich medium (1\% yeast extract, $1.6 \%$ peptone, $0.5 \% \mathrm{NaCl}$ ) were performed from a late-exponential overnight culture obtained in liquid 2YT medium. B. melitensis $16 \mathrm{M}$ strains grew with shaking at $37^{\circ} \mathrm{C}$ in rich medium containing appropriate antibiotics from an initial $\mathrm{OD}_{600}$ of 0.05. C. crescentus $\mathrm{CB} 15 \mathrm{~N}$ grew in peptone-yeast extract (PYE complex media) at $30^{\circ} \mathrm{C}$. Antibiotics were used at the following final concentrations: kanamycin, $50 \mu \mathrm{g} \mathrm{ml}^{-1}$; nalidixic acid, $25 \mu \mathrm{g} \mathrm{ml}^{-1}$.

\section{Flagellum staining and visualization by phase-contrast microscopy}

Bacterial flagella were stained using the "Ryu staining" method as described previously [17-19]. The Ryu stain has two components. Solution I (the mordant) contains $10 \mathrm{ml}$ of $5 \%$ aqueous solution of phenol, $2 \mathrm{~g}$ of tannic acid, and $10 \mathrm{ml}$ of saturated aqueous solution of aluminum potassium sulfate-12 hydrate. Solution II (the stain) is a saturated ethanolic solution of crystal violet
( $3 \mathrm{~g}$ in $25 \mathrm{ml}$ of $95 \%$ ethanol). The final stain was prepared just before use by mixing 1 part of solution II with 10 parts of solution I and then by filtering the mixture through filter paper to remove coarse precipitate. A drop of cell culture was transferred onto the clean slide and covered with a cover slip. After 5 to $10 \mathrm{~min}$, two drops of Ryu stain were applied to the edge of the cover slip and flowed under the cover slip by capillarity and mixed with the cell suspension. The cells were examined for flagella after 5 to $15 \mathrm{~min}$ at room temperature under a phase-contrast microscope. The edges of the cover slip on the slide were sealed with nail varnish.

\section{Visualization of the flagella by transmission electron microscopy (TEM)}

The bacteria were grown in rich medium at $37^{\circ} \mathrm{C}$ to an $\mathrm{OD}_{600}$ of 0.25 . Bacteria were centrifuged at 1000 r.p.m. for $20 \mathrm{~min}$ (Jouan), washed in PBS and fixed for $20 \mathrm{~min}$ in $50 \mu \mathrm{l}$ of $4 \%$ paraformaldehyde $\mathrm{pH}$ 7.3. Samples were stored at $4^{\circ} \mathrm{C}$. A drop (15 to $\left.35 \mu \mathrm{l}\right)$ of a solution of $1 \%$ Alcian blue was placed on a sheet of Parafilm. A carbon Formvar-coated grid was placed on a drop of solution for $5 \mathrm{~min}$, carbon side down, washed five times in distilled water and then placed on a drop of bacterial suspension for $10 \mathrm{~min}$ on the same parafilm sheet. Grids with adherent cells were either (i) negatively stained for direct visualization on transmission electron microscope (TEM) or (ii) labeled with the anti-Brucella LPS O-chain, M epitope, mAb A156b3b2 [20,21] before staining as described previsously by Fretin et al.[1]. For immunolabeling, after $10 \mathrm{~min}$ on the drop of bacterial suspension, the carbon Formvar-coated grid was placed onto drops (15 to $35 \mu \mathrm{l}$ ) of the following reagents on the same parafilm sheet: 5 washes in phosphate-buffered saline (PBS)-glycine 5\% (3 sec each), PBS-bovine serum albumin (BSA)(1 min), monoclonal antibody A156b3b2 diluted $1 / 20$ in PBS-BSA 5\% (1 h), five washes in PBS (10 sec each), rabbit anti-mouse immunoglobulin conjugated to $\pm 15 \mathrm{~nm}$ colloidal gold diluted $1 / 20$ in PBS-

Table 1 Bacterial strains

\begin{tabular}{|c|c|c|}
\hline Strain $^{a}$ & Description & Source of reference \\
\hline \multicolumn{3}{|l|}{ B. melitensis strains } \\
\hline $16 \mathrm{M} \mathrm{Nal}^{\mathrm{r}}$ & $\begin{array}{l}\text { Spontaneous Nal' strain of B. melitensis } 16 \mathrm{M} \text { obtained from } \\
\text { A. P. MacMillan, Central Veterinary Laboratory, Weybridge, United Kingdom }\end{array}$ & Laboratory collection \\
\hline ftcR mutant & B. melitensis $16 \mathrm{M} \Delta \mathrm{ftc} R: \mathrm{Kan}^{\mathrm{r}}$ & [13] \\
\hline flif mutant & B. melitensis $16 \mathrm{M} \Delta$ fliF::Kan ${ }^{r}$ & Ferooz et al. ${ }^{b}$ \\
\hline flgE mutant & B. melitensis $16 \mathrm{M} \Delta$ flgE::Kan ${ }^{r}$ & Ferooz et al. ${ }^{b}$ \\
\hline flic mutant & B. melitensis $16 \mathrm{M} \triangle \mathrm{fliC}:: \mathrm{Kan}^{\mathrm{r}}$ & Ferooz et al. ${ }^{b}$ \\
\hline virB mutant & B. melitensis $16 \mathrm{M} \Delta$ virB & {$[22]$} \\
\hline \multicolumn{3}{|l|}{ C. crescentus strain } \\
\hline NA1000 & syn-1000, synchronizable variant of strain CB15 & [53] \\
\hline
\end{tabular}

\footnotetext{
${ }^{a} \mathrm{Nal}^{\mathrm{r}}$, nalidixic acid resistant; Kan', kanamycin resistant. ${ }^{b}$ Submitted for publication.
} 
BSA (1 h), three washes in PBS (10 sec each), 2 washes in distilled water (10 sec each). After a completed treatment protocol, the grid was negatively stained with $2 \%$ aqueous solution of uranyl acetate for $10 \mathrm{sec}$, the excess fluid was removed with a filter paper, and the grid was air dried. Specimens were examined using a Philips Technai 10 TEM. Note that protein A-colloidal gold were also used instead of rabbit anti-mouse immunoglobulin with the same results.

\section{Results}

The Ryu staining is a simple technique for the detection of the flagellum of Brucella melitensis

Due to the short period of flagellar production (only at early exponential growth) and the low percentage of flagellated bacteria in $B$. melitensis, the visualization of the flagellum by TEM is difficult [1]. To easily detect the flagellated Brucella, we used the Ryu staining. An advantage of that technique is that the flagellum of $B$. melitensis can be visualized directly without any prior centrifugation (required for the TEM technique), minimizing the manipulation of the culture containing the pathogen. As positive control, we used Caulobacter crescentus because its flagellar expression is cell-cycle dependent and the flagella were previously visualized by Ryu staining [19]. We were able to visualize the flagellum of $B$. melitensis using the Ryu staining by phasecontrast microscopy (Figure 1A). Although the number of flagellated $B$. melitensis in the population is fewer than the flagellated C. crescentus (Figure 1B), the stained flagellum produced by $B$. melitensis is clearly detected by optical microscope. This result demonstrates that the Ryu staining is a simple technique allowing a rapid visualization of the flagellum of $B$. melitensis and with minimal sample manipulation.

\section{Ultrastructure analysis of the sheathed flagellum of B. melitensis by TEM}

We used the transmission electron miscroscopy (TEM) to analyze precisely the ultrastructure of the flagellum in B. melitensis. A sample of a B. melitensis culture at the early exponential growth phase in rich medium was stained with uranyl acetate $2 \%$ and visualized by TEM as described in the Materials and Methods section. We also labeled the bacteria with an anti-Brucella lipopolysaccharide (LPS) antibody and confirmed the presence of LPS on both the cell surface and the sheathed flagellum of B. melitensis (Figure 1C). B. melitensis produces a polar sheathed flagellum of about $50 \mathrm{~nm}$ diameter, showing an inner filament of about $11 \mathrm{~nm}$ diameter clearly surrounded by a sheath, which seems to be most likely a continuous extension of the bacterial outer membrane (Figure 1C and 2). As usually seen in other bacterial species producing a sheathed flagellum, the

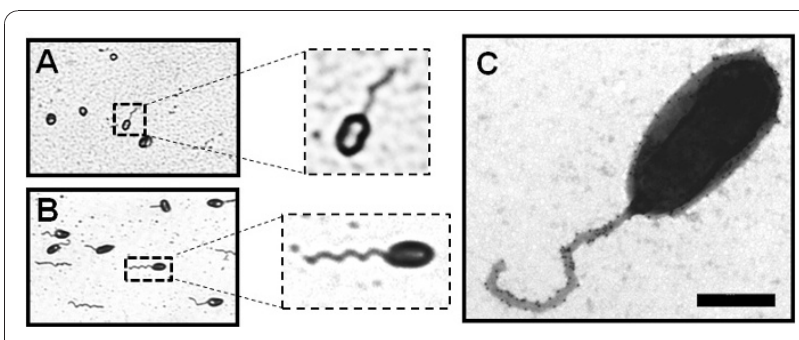

Figure 1 Visualization of flagella. Ryu staining of $B$. melitensis (A) C. crescentus (B) observed by phase-contrast microscopy. The samples were treated by the Ryu staining method as described in Materials and Methods. A flagellated bacterium is enlarged in a dotted square. (C) Negative-staining EM images of the sheathed polar flagellum of B. melitensis stained with uranyl acetate $2 \%$ and labeled with anti-LPS antibody conjugated to $\pm 15 \mathrm{~nm}$ gold particles. Bar, $500 \mathrm{~nm}$.

flagellum of B. melitensis is ending by a club-like structure (Figure 3A). A polar bended structure is also usually observed, like a nascent flagellum during the first steps of flagellar assembly (Figure 3B). This bended structure, and sometimes a flagellum, is visualized at the septum of division between two daughter cells, suggesting that flagellar assembly occurs at this site (Figure 3C). Taken together, these data clearly demonstrate that the appendage produces by B. melitensis has the typical features of the sheathed flagella and not a pilus-like structure or a remaining part of the flagellum.

\section{The sheath production is not dependent of the $f t c R$ pathway and the flagellar structure}

To determine whether the mutation of flagellar genes affect flagellar assembly, $\Delta f l i F, \Delta f l g E$ and $\Delta f l i C$ mutants were analyzed by TEM. These mutants were created by gene replacement with the aphA4 cassette (J. Ferooz et al., unpublished). Surprisingly, these three mutants still produce a filamentous structure (Figure 4A, B and $4 C)$. We previously demonstrated that FlgE and FliC protein cannot be detected by Western blot analysis in $\triangle f l g E$ and $\triangle f l i C$ respectively. Therefore, we propose that the appendage observed in $\triangle f l i F, \triangle f l g E$ and $\triangle f l i C$ is an empty sheath. The genome of $B$. melitensis contains the clusters of genes coding for only two extracellular structures: a type IV secretion system (T4SS) expressed at the stationary growth phase and a flagellum. In order to know whether the structure seen is a T4SS or not, a $\triangle \operatorname{vir} B$ mutant was visualized by TEM. This $\Delta v \operatorname{ir} B$ mutant was made by removing the 12 open reading frames (ORFs) encoding the T4SS of B. melitensis $16 \mathrm{M}$ [22]. As seen in the wild-type strain (Figure 4D), $\Delta v i r B$ also produces a similar flagellar structure at the early exponential growth phase (Figure 4E). This result demonstrates that the extracellular appendage observed in flagellar mutants is not a T4SS. 

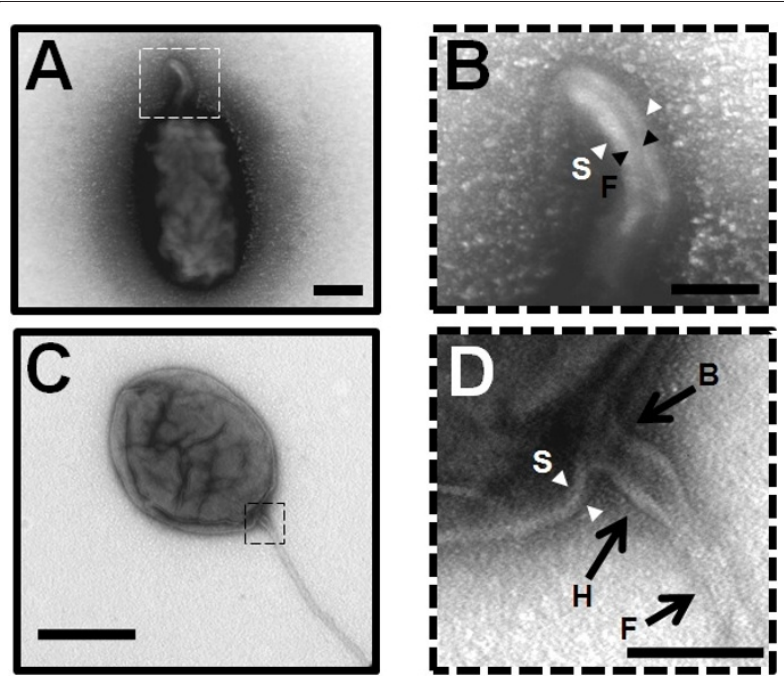

Figure 2 Visualization of the flagellar sheath. (A and $B$ ) Negative-staining EM images of the sheathed polar flagellum of $B$. melitensis stained with uranyl acetate $2 \%$. (B)The central filament is indicated by black arrowheads with $\mathrm{F}$ and the sheath by white arrowheads with S. Bar, $200 \mathrm{~nm}$. (C and D) Capture of the basal region of the flagellum. The image shows the basal body region ( $B$ with black arrow), the hook ( $\mathrm{H}$ with black arrow) and is finished by the filament ( $F$ with black arrow). The structure is surrounded by a sheath extended from the outer membrane ( $S$, white arrowheads). Bar, $100 \mathrm{~nm}$. The images B and D are enlarged from the dotted square in image $A$ and $C$ respectively.

The flagellar expression is not affected by mutation of the structural genes, indeed $\Delta f l i F$ and $\triangle f l g E$ still produce the flagellin FliC (J. Ferooz et al., unpublished). However, the flagellar master regulator FtcR is needed for fliF expression and the FlgE and FliC synthesis [13]. By intensively observing $\triangle f t c R$ by TEM, we also found some bacteria producing a filament-like structure, suggesting that sheath synthesis and assembly is likely independent of the FtcR pathway (Figure 4F).
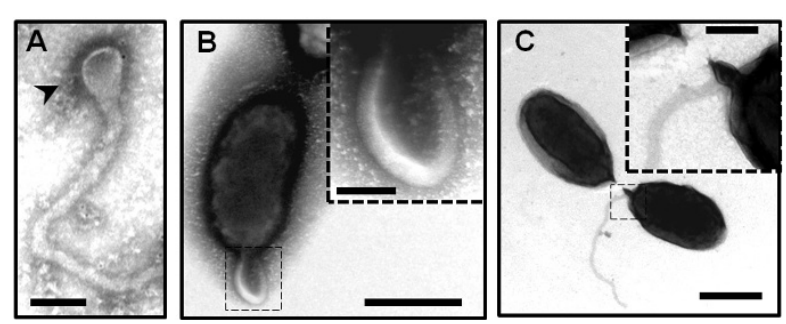

Figure 3 Negative-staining EM images of the sheathed polar flagellum from $B$. melitensis stained with uranyl acetate $2 \%$. (A) The flagellum is ended by a club-like structure (black arrowhead). (B) Image of a curve structure at the pole of the cell. (C) Predivisional cells exhibited a flagellum at the septum division. A higher magnification of a part of flagellum (black square) is showing (dotted square). Bars, $500 \mathrm{~nm}$ in B and C; Bars, $100 \mathrm{~nm}$ (A, dotted squares in $\mathrm{B}$ and $\mathrm{C}$ ).

\section{Discussion and Conclusions}

Although it was demonstrated that B. melitensis produces a polar sheathed flagellum under specific conditions [1], there were still some doubts concerning the production of a classical flagellum by Brucella [5,23]. The conditions in which the flagellum is observed are not optimal because Brucella produces a flagellum only at the early exponential growth phase in rich medium [1]. Moreover, Brucella must be handled according to level 3 biosafety precautions [24], making difficult its manipulation for the preparation of sample for TEM analysis. This is the reason why we tested the Ryu staining technique, that allows an easier detection of flagellum than TEM as described in several flagellated bacteria such as C. crescentus, L. monocytogenes, Bacillus subtilis and Salmonella Typhi [19,25-27]. Interestingly, even with a low number of flagellated bacteria, this technique allows a quick and direct manipulation of the culture before the extinction of flagellar expression. In this work, we showed that the flagellum of B. melitensis can be easily visualized using the Ryu staining.

The structure of the flagellum produces by $B$. melitensis was analyzed by the TEM technique and several features of the sheathed flagella of other species were highlighted. At the present time, little is known about the formation, composition or function of flagellar sheaths in bacteria, and interestingly, Brucella is the only one rhizobiale to produce a sheathed flagellum $[28,29]$. Due to the sheath around the filament, the visible flagellum of B. melitensis has a diameter of $50 \mathrm{~nm}$, which is larger than an unsheathed flagellum. However, the diameter of the bacterial filament is usually about $20 \mathrm{~nm}$ but we showed that the diameter of the inner filament in the sheath of $B$. melitensis is only $11 \mathrm{~nm}$. This smaller diameter could be linked to the shorter amino acid sequence of the unique flagellin composed of only 282 amino acids in B. melitensis. In comparison, the flagellin sequence of $E$. coli, S. enterica serovar Typhimurium and Pseudomonas aeruginosa are between 488 and 498 amino acids.

Among the features of sheathed flagellum, the shape at the end of the flagella of $B$. melitensis is similar to a club-like structure, also described in other bacteria like B. bacteriovorus, H. pylori and V. fischeri [30-32]. This extension can be viewed as the continuity of the sheath at the end of the filament. The genome of Brucella lacks the FliD (or HAP2) homologue, a protein involved in the flagellin assembly at the top of the filament. One hypothetical function of this club-like structure could be the formation of a confined space facilitating the selfassembly of flagellin monomers into a filament, despite the lack of a FliD homologue. Similarly in Vibrio alginolyticus, it was assumed that the sheath could trap 

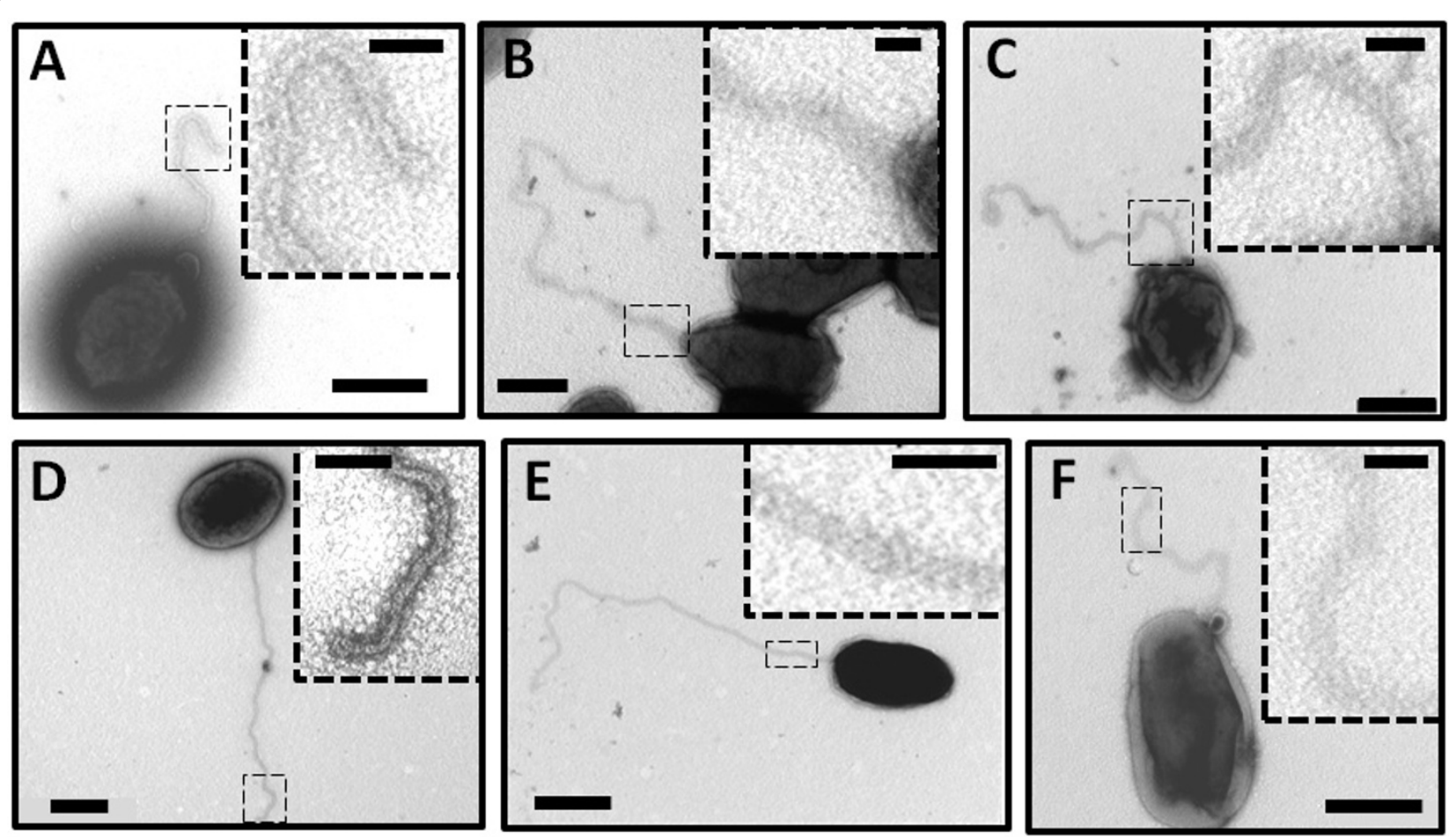

Figure 4 Detection of a flagellum in Brucella's flagellar mutants. Negative-staining EM images of the wild-type (D) compared to $\triangle f l i F$ (A), $\triangle f l g E(B), \triangle f l i C(C), \triangle v i r B(E)$ and $\triangle f t c R(F)$ stained with uranyl acetate $2 \%$. In dotted squares: higher magnification of a flagellum section. Bars, 500 $\mathrm{nm}$ and $100 \mathrm{~nm}$ in dotted squares.

excreted flagellin to allow polymerization independently of FliD [33]. Secondly, the sheath of the flagellum of B. melitensis is likely an extension of the outer membrane and contains LPS, which is also observed in H. pylori, B. bacteriovorus and some Vibrio spp., [1,32,34-38]. Even if the sheath contains LPS, the sheath composition of Vibrio and Helicobacter is different from the outer membrane $[30,39,40]$. To the best of our knowledge, all these features have never been observed in a pilus-like structure, confirming that this appendage is a flagellum and not a pilus or flagellum-like structure.

Similarly to other $\alpha$-proteobacteria, Brucella and C. crescentus are morphologically asymmetric [41]. C. crescentus couples flagellar biogenesis with cell cycle allowing the production of a flagellum at the swarmer pole of predivisional cell and a stalk at the other pole [11]. Surprisingly, we occasionally observed a bended structure or a flagellum at the septum division of $B$. melitensis rather than at the poles of predivisional cells. The localization of the flagellum at the septum of division is rarely observed in bacteria but is not unusual and is described in B. bacteriovorus and Treponema phagedenis $[42,43]$.

In the last part of this work, we demonstrated that production of the sheath is probably unlinked to flagellar assembly in B. melitensis. Indeed, $\Delta f l i F, \Delta f l g E$ and $\Delta f l i C$ structural flagellar mutants still produce a filamentous appendage despite the absence of FlgE or FiC proteins. However, persistence of an empty sheath in flagellar mutants was often described in bacteria producing a sheathed flagellum as Vibrio species and $H$. pylori [44-48]. In B. bacteriovorus, deletion of flagellin fliC3 caused the synthesis of copious, disordered, tubular material resembling outer membrane $[49,50]$. The authors suggest that this structure is a disordered sheath without a normal flagellum inside. It is important to note that counting the number of flagellated bacteria in the population of the mutants in order to estimate a percentage of flagellation compared to the wild-type strain is not relevant due to the variability and the low number of flagellated bacteria detected between samples. Thus, it is possible that the population of flagellar mutants is less flagellated than the wild type population, but better conditions to enhance flagellation of $B$. melitensis will be needed.

In spite the fact that FtcR is the master regulator of flagellar assembly in Brucella, persistence of sheath production in $\triangle f t c R$ mutant also demonstrate that sheath expression is not dependent of FtcR and suggests that another unknown regulator is involved. Since the sheath surrounds the filament and is produced at one pole of the cell, even in flagellar mutants, it is possible that a flagellar pole marker coordinates both flagellum and 
sheath biogenesis at the cell pole before the FtcR activation. In Vibrio alginolyticus and C. crescentus, the localization of the flagellum at the pole is dictated by FlhF and PflI regulators respectively [51,52]. Polar localization of the pole marker PflI is independent of FliF, whose oligomerization into the MS-ring probably allows the definition of the site of flagellar synthesis, suggesting that PflI acts before or independently of this event [52]. Similarly, a regulator could couple flagellar assembly and sheath production independently of FtcR in $B$. melitensis.

Altogether, the data presented in this study proved that $B$. melitensis produces a flagellum with the characteristics of sheathed flagella described in other organisms. Flagellar assembly and sheath production are a complex regulatory mechanism that remains to be further investigated to gain a better understanding of the flagellum's function during Brucella's infection.

\section{Acknowledgements}

We thank Dr Valérie Haine for her critical and careful reading of this manuscript and helpful discussion. We are grateful to Bettina Battisti for the helpful manuscript revision. We thank the anonymous reviewers for their insightful comments and suggestions. We acknowledge the 'Service Interfacultaire de Microscopie Electronique' of the University of Namur and for its expertise in TEM. This work was supported by grants to Jonathan Ferooz from the Fonds Adrien Bauchau and the FNRS (Fonds National de la Recherche Scientifique). This work was supported by the Commission of the European Communities (contract no. QLK2-CT-1999-00014), the FRFC (Fonds de la Recherche Fondamentale Collective, conventions 2.4521.04 and 2.4521.08) and the ARC fellowship (Actions de Recherches Concertées, conventions 04/09-325 and 08/13-015). Jonathan Ferooz held a Belgian specialization grant from the FRIA (Fonds pour la Formation à la Recherche dans I'Industrie et dans l'Agriculture).

\section{Author details}

'Unité de Recherche en Biologie Moléculaire (URBM), Facultés Universitaires Notre-Dame de la Paix (FUNDP), 61 rue de Bruxelles, B-5000 Namur, Belgium. ${ }^{2}$ GlaxoSmithKline Biologicals, 20 Avenue Fleming, B-1300 Wavre, Belgium.

\section{Authors' contributions}

JF and JJL designed the experiments and interpreted the data. JF performed the experiments. JF wrote the manuscript. All authors read and approved the final manuscript.

\section{Competing interests}

The authors declare that they have no competing interests.

Received: 12 September 2010 Accepted: 9 December 2010 Published: 9 December 2010

\section{References}

1. Fretin D, Fauconnier A, Kohler S, Halling S, Leonard S, Nijskens C, Ferooz J, Lestrate P, Delrue RM, Danese I, et al: The sheathed flagellum of Brucella melitensis is involved in persistence in a murine model of infection. Cell Microbiol 2005, 7:687-98.

2. Ferooz J: The flagellum of Brucella melitensis: caracterization of the flagellar structure and regulation (in french). Namur: Facultés universitaires Notre-Dame de la Paix (FUNDP) 2009, PhD thesis.

3. Paulsen IT, Seshadri R, Nelson KE, Eisen JA, Heidelberg JF, Read TD, Dodson RJ, Umayam L, Brinkac LM, Beanan MJ, et al: The Brucella suis genome reveals fundamental similarities between animal and plant pathogens and symbionts. Proc Natl Acad Sci USA 2002, 99:13148-53.
4. DelVecchio VG, Kapatral V, Redkar RJ, Patra G, Mujer C, Los T, Ivanova N, Anderson I, Bhattacharyya A, Lykidis A, et al: The genome sequence of the facultative intracellular pathogen Brucella melitensis. Proc Natl Acad Sci USA 2002, 99:443-8.

5. Chain PS, Comerci DJ, Tolmasky ME, Larimer FW, Malfatti SA, Vergez LM, Aguero F, Land ML, Ugalde RA, Garcia E: Whole-genome analyses of speciation events in pathogenic Brucellae. Infect Immun 2005, 73:8353-61.

6. Tsolis RM, Seshadri R, Santos RL, Sangari FJ, Lobo JM, de Jong MF, Ren Q, Myers G, Brinkac LM, Nelson WC, et al: Genome degradation in Brucella ovis corresponds with narrowing of its host range and tissue tropism. PLoS One 2009, 4:e5519.

7. Audic S, Lescot M, Claverie JM, Scholz HC: Brucella microti: the genome sequence of an emerging pathogen. BMC Genomics 2009, 10:352.

8. Chevance FF, Hughes KT: Coordinating assembly of a bacterial macromolecular machine. Nat Rev Microbiol 2008, 6:455-65.

9. McCarter LL: Regulation of flagella. Curr Opin Microbio/ 2006, 9:180-6.

10. Aldridge $P$, Hughes $K T$ : Regulation of flagellar assembly. Curr Opin Microbiol 2002, 5:160-5.

11. England JC, Gober JW: Cell cycle control of cell morphogenesis in Caulobacter. Curr Opin Microbiol 2001, 4:674-80.

12. Soutourina $\mathrm{OA}$, Bertin PN: Regulation cascade of flagellar expression in Gram-negative bacteria. FEMS Microbiol Rev 2003, 27:505-23.

13. Leonard S, Ferooz J, Haine V, Danese I, Fretin D, Tibor A, de Walque S, De Bolle $X$, Letesson JJ: FtcR is a new master regulator of the flagellar system of Brucella melitensis $16 \mathrm{M}$ with homologs in Rhizobiaceae. J Bacteriol 2007, 189:131-41.

14. Rambow-Larsen AA, Rajashekara G, Petersen E, Splitter G: Putative quorumsensing regulator BIxR of Brucella melitensis regulates virulence factors including the type IV secretion system and flagella. J Bacterio/ 2008, 190:3274-82

15. Delrue RM, Deschamps C, Leonard S, Nijskens C, Danese I, Schaus JM, Bonnot S, Ferooz J, Tibor A, De Bolle X, et al: A quorum-sensing regulator controls expression of both the type IV secretion system and the flagellar apparatus of Brucella melitensis. Cell Microbiol 2005, 7:1151-61.

16. Uzureau S, Godefroid M, Deschamps C, Lemaire J, De Bolle X, Letesson JJ: Mutations of the quorum sensing-dependent regulator $\mathrm{VjbR}$ lead to drastic surface modifications in Brucella melitensis. J Bacteriol 2007, 189:6035-47.

17. Ryu E: A simple method of staining bacterial flagella. Kitasato Arch Exp Med 1937, 14:218-219.

18. Kodaka H, Armfield AY, Lombard GL, Dowell VR Jr: Practical procedure for demonstrating bacterial flagella. J Clin Microbiol 1982, 16:948-52.

19. Heimbrook ME, Wang WL, Campbell G: Staining bacterial flagella easily. J Clin Microbiol 1989, 27:2612-5.

20. Weynants V, Gilson D, Cloeckaert A, Tibor A, Denoel PA, Godfroid F, Limet JN, Letesson JJ: Characterization of smooth lipopolysaccharides and $\mathrm{O}$ polysaccharides of Brucella species by competition binding assays with monoclonal antibodies. Infect Immun 1997, 65:1939-43.

21. Cloeckaert A, Zygmunt MS, Dubray G, Limet JN: Characterization of Opolysaccharide specific monoclonal antibodies derived from mice infected with the rough Brucella melitensis strain B115. J Gen Microbiol 1993, 139:1551-6.

22. Nijskens C, Copin R, De Bolle $X$, Letesson JJ: Intracellular rescuing of a $B$. melitensis $16 \mathrm{M}$ virB mutant by co-infection with a wild type strain. Microb Pathog 2008, 45:134-41.

23. Pallen MJ, Matzke NJ: From The Origin of Species to the origin of bacterial flagella. Nat Rev Microbiol 2006, 4:784-90.

24. Robichaud S, Libman M, Behr M, Rubin E: Prevention of laboratoryacquired brucellosis. Clin Infect Dis 2004, 38:e119-22.

25. Todhanakasem T, Young GM: Loss of flagellum-based motility by Listeria monocytogenes results in formation of hyperbiofilms. J Bacterio/ 2008, 190:6030-4.

26. Kinsinger RF, Shirk MC, Fall R: Rapid surface motility in Bacillus subtilis is dependent on extracellular surfactin and potassium ion. J Bacterio/ 2003, 185:5627-31.

27. Ramirez K, Capozzo AV, Lloyd SA, Sztein MB, Nataro JP, Pasetti MF: Mucosally delivered Salmonella typhi expressing the Yersinia pestis F1 antigen elicits mucosal and systemic immunity early in life and primes the neonatal immune system for a vigorous anamnestic response to parenteral F1 boost. J Immunol 2009, 182:1211-22 
28. MCCarter LL: Polar flagellar motility of the Vibrionaceae. Microbiol Mol Biol Rev 2001, 65:445-62, table of contents.

29. Sjoblad RD, Emala CW, Doetsch RN: Invited review: bacterial flagellar sheaths: structures in search of a function. Cell Motil 1983, 3:93-103.

30. Thomashow LS, Rittenberg SC: Isolation and composition of sheathed flagella from Bdellovibrio bacteriovorus 109J. J Bacteriol 1985, 163:1047-54.

31. Geis $G$, Leying H, Suerbaum S, Mai U, Opferkuch W: Ultrastructure and chemical analysis of Campylobacter pylori flagella. J Clin Microbiol 1989, 27:436-41.

32. Allen RD, Baumann P: Structure and arrangement of flagella in species of the genus Beneckea and Photobacterium fischeri. J Bacteriol 1971, 107:295-302.

33. Nishioka N, Furuno M, Kawagishi I, Homma M: Flagellin-containing membrane vesicles excreted from Vibrio alginolyticus mutants lacking a polar-flagellar filament. J Biochem 1998, 123:1169-73.

34. Geis G, Suerbaum S, Forsthoff B, Leying H, Opferkuch W: Ultrastructure and biochemical studies of the flagellar sheath of Helicobacter pylori. J Med Microbiol 1993, 38:371-7.

35. Fuerst JA, Perry JW: Demonstration of lipopolysaccharide on sheathed flagella of Vibrio cholerae 0:1 by protein A-gold immunoelectron microscopy. J Bacteriol 1988, 170:1488-94.

36. Millikan DS, Ruby EG: Vibrio fischeri flagellin A is essential for normal motility and for symbiotic competence during initial squid light organ colonization. J Bacteriol 2004, 186:4315-25.

37. Thomashow LS, Rittenberg SC: Waveform analysis and structure of flagella and basal complexes from Bdellovibrio bacteriovorus 109J. J Bacteriol 1985, 163:1038-46.

38. Glauert AM, Kerridge D, Horne RW: The Fine Structure and Mode of Attachment of the Sheathed Flagellum of Vibrio Metchnikovii. I Cell Biol 1963, 18:327-36

39. Doig P, Trust TJ: Identification of surface-exposed outer membrane antigens of Helicobacter pylori. Infect Immun 1994, 62:4526-33.

40. Jones AC, Logan RP, Foynes S, Cockayne A, Wren BW, Penn CW: A flagellar sheath protein of Helicobacter pylori is identical to $\mathrm{HpaA}$, a putative $\mathrm{N}$ acetylneuraminyllactose-binding hemagglutinin, but is not an adhesin for AGS cells. J Bacteriol 1997, 179:5643-7.

41. Hallez R, Bellefontaine AF, Letesson JJ, De Bolle X: Morphological and functional asymmetry in alpha-proteobacteria. Trends Microbiol 2004, 12:361-5.

42. Burnham JC, Hashimoto T, Conti SF: Ultrastructure and cell division of a facultatively parasitic strain of Bdellovibrio bacteriovorus. J Bacterio/ 1970 101:997-1004.

43. Izard J, Samsonoff WA, Kinoshita MB, Limberger RJ: Genetic and structural analyses of cytoplasmic filaments of wild-type Treponema phagedenis and a flagellar filament-deficient mutant. J Bacteriol 1999, 181:6739-46.

44. Richardson K: Roles of motility and flagellar structure in pathogenicity of Vibrio cholerae: analysis of motility mutants in three animal models. Infect Immun 1991, 59:2727-36.

45. Richardson K, Nixon L, Mostow P, Kaper JB, Michalski J: Transposoninduced non-motile mutants of Vibrio cholerae. J Gen Microbiol 1990, 136:717-25.

46. Josenhans C, Labigne A, Suerbaum S: Comparative ultrastructural and functional studies of Helicobacter pylori and Helicobacter mustelae flagellin mutants: both flagellin subunits, FlaA and FlaB, are necessary for full motility in Helicobacter species. J Bacteriol 1995, 177:3010-20.

47. Ryan KA, Karim N, Worku M, Penn CW, OToole PW: Helicobacter pylori flagellar hook-filament transition is controlled by a Flik functional homolog encoded by the gene HP0906. J Bacteriol 2005, 187:5742-50.

48. Schirm M, Soo EC, Aubry AJ, Austin J, Thibault P, Logan SM: Structural, genetic and functional characterization of the flagellin glycosylation process in Helicobacter pylori. Mol Microbiol 2003, 48:1579-92.

49. Lambert C, Evans KJ, Till R, Hobley L, Capeness M, Rendulic S, Schuster SC, Aizawa S, Sockett RE: Characterizing the flagellar filament and the role of motility in bacterial prey-penetration by Bdellovibrio bacteriovorus. Mol Microbiol 2006, 60:274-86

50. Iida Y, Hobley L, Lambert C, Fenton AK, Sockett RE, Aizawa S: Roles of multiple flagellins in flagellar formation and flagellar growth post bdelloplast lysis in Bdellovibrio bacteriovorus. J Mol Biol 2009, 394:1011-21.

51. Kusumoto A, Shinohara A, Terashima H, Kojima S, Yakushi T, Homma M: Collaboration of FlhF and FlhG to regulate polar-flagella number and localization in Vibrio alginolyticus. Microbiology 2008, 154:1390-9.
52. Obuchowski PL, Jacobs-Wagner C: Pfll, a protein involved in flagellar positioning in Caulobacter crescentus. J Bacteriol 2008, 190:1718-29.

53. Evinger M, Agabian N: Envelope-associated nucleoid from Caulobacter crescentus stalked and swarmer cells. J Bacteriol 1977, 132:294-301.

doi:10.1186/1756-0500-3-333

Cite this article as: Ferooz and Letesson: Morphological analysis of the sheathed flagellum of Brucella melitensis. BMC Research Notes 2010 3:333.

\section{Submit your next manuscript to BioMed Central and take full advantage of:}

- Convenient online submission

- Thorough peer review

- No space constraints or color figure charges

- Immediate publication on acceptance

- Inclusion in PubMed, CAS, Scopus and Google Scholar

- Research which is freely available for redistribution

Submit your manuscript at www.biomedcentral.com/submit
C Biomed Central 